\title{
İnönü Üniversitesi Tip ve Mühendislik Fakültesi Öğrencilerinin Afet Konusundaki Bilgi, Tutum ve Davranışları
}

\author{
Knowledge, Attitudes and Behaviours About Disasters at \\ Inonu University of Medical and Engineering Students \\ Esra Yiğit ${ }^{1}$, Gülseda Boz ${ }^{1}$, Ayşe Gökçe², Ali Özer ${ }^{1}$ \\ ${ }^{1}$ İnönü Üniversitesi Tip Fakültesi Halk Sağlığı Anabilim Dalı Malatya/Türkiye \\ ${ }^{2}$ Bingöl İl Sağlık Müdürlüğü Bingöl/Türkiye \\ Yazıșma Adresi / Correspondence: \\ Ayşe Gökçe \\ Yenişehir, Güldiken Sokak, 12000 Bingöl İl Sağllk Müdürlüğü Merkez/Bingöl \\ T: +905343040795 E-mail : abaran88@hotmail.com \\ Geliş Tarihi / Received : 02.03.2020 Kabul Tarihi / Accepted : 28.09.2020 \\ Orcid : \\ Esra Yiğit https://orcid.org/0000-0002-8467-6002 \\ Gülseda Boz https://orcid.org/0000-0003-1959-0226 \\ Ayșe Gökçe https://orcid.org/0000-0002-6477-3518 \\ Ali Özer https://orcid.org/0000-0002-7144-4915 \\ ( Sakarya Tip Dergisi / Sakarya Med J 2020, 10(4):580-586 ) DOI: 10.31832/smj.696069
}

Öz

Amaç Uluslararası Afet Veritabanı verilerine göre, 2018 yılında dünyada 68 milyondan fazla insanı etkileyen, 11804 ölümle sonuçlanan 315 doğal afet olayı yaşanmıştır. Meydana gelebilecek bir afete karșı hazırlıklı olunarak, afetin doğurabileceği olumsuz sonuçları en aza indirmek mümkündür. Çalısmamızda; Tip ve Mühendislik fakültelerinde öğrenim gören öğrencilerin afet konusundaki bilgi, tutum ve davranışlarının saptanması amaçlanmıştır.

Gereç ve Kesitsel tipteki bu çalıșmanın evrenini; Tip ve Mühendislik Fakültelerindeki öğrenciler olușturmaktadır. Örneklem büyüklüğü; \%95 güven aralığında \%80 güçle minimum

Yöntem 297 olarak hesaplanmıștır. Anket formunda sosyodemografik sorular, bireyin afet konusundaki bilgi, tutum ve davranışlarını ölçen sorular ve Genel Afet Hazırlık İnanç Ölçeği (GAHIÖ) yer almaktadır. İstatistiksel analizlerde; Student T Testi, One Way Anova testleri kullanılmıștır.

Bulgular Araştırmaya katılan öğrencilerden $\% 52,85$ ’inin afet yaşadığı ve en sık yaşadıkları afet türünün \%46,20 oranı ile deprem olduğu görülmüștür. Afet ile ilgili eğitim alan

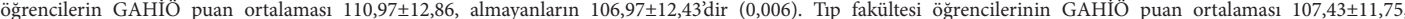

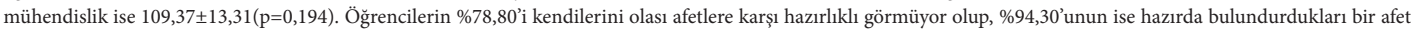
çantası yoktur.

Sonuç Öğrencilerin afet çantası bulundurma oranlarının bu denli düşük olması öneminin yeteri kadar farkında olmadıklarını göstermektedir. Eğitim alan öğrencilerin bilgi tutum ve davranıșlarındaki olumlu değișim de göz önünde bulundurulduğunda, öğrencilerin afetle ilgili düzenli aralıklarla eğitim ve tatbikatlarla desteklenmesi uygun olabilir

Anahtar Afetler; Öğrenciler; Bilgi Düzeyi.

Kelimeler

Abstract

Objective According to data from The International Disasters Database in 2018, 315 natural disasters occurred; affecting more than 68 million people worldwide and resulting in 11804 deaths. It is possible to minimize the negative consequences of the disaster by being prepared for a disaster that may occur. In our study, we aimed to determine the knowledge, attitudes and behaviors of the students about disasters receiving education in Medical and Engineering faculties.

Materials The universe of this cross-sectional study consists of students in the Faculty of Medicine and Engineering. The sample size was calculated minimum as 297 with $80 \%$ power and $95 \%$ confidence and methods interval. The questionnaire form includes sociodemographic questions, questions measuring the individual's knowledge, attitudes and behaviors about the disaster and General Disaster Preparedness Belief Scale (GDPBS). In statistical analysis, student t-Test and One-Way ANOVA tests were used.

Results The mean GDPBS score of the students who receive education about the disaster is $110.97 \pm 12.86$ and those who do not receive is $106.97 \pm 12.43$ ( $p=0.006$ ). The mean GDPBS scores of the students of the medical faculties are $107.43 \pm 11.75$, engineering is $109.37 \pm 13.31$ ( $p=0.194$ ). $78.80 \%$ of students do not consider themselves prepared for possible disasters, $94.30 \%$ do not have a disaster bag.

Conclusion The fact that disaster bag rates in students are so low indicates that they are not aware of the importance of disaster. Considering the positive change of students receiving education, it may be appropriate to support the students with regular trainings related to disasters.

Keywords Disaster; Students; Knowledge 


\section{GIIRIŞ}

Afetin günümüzde bir çok tanımı mevcut olmakla beraber Dünya Sağlık Örgütü afeti; "Beklenmeyen, kurumun olanakları ve kapasitesini aşan, normal işleyişi bozan, dışarıdan yardım gerektiren ani ekolojik olgu” olarak tanımlamaktadır. ${ }^{1}$ Aynı zamanda afet; "Toplumun tamamı için fiziksel, ekonomik ve sosyal kayıplar doğuran, normal hayatı ve insan faaliyetlerini durduran veya kesintiye uğratan, etkilenen toplumun baş etme kapasitesinin yeterli olmadığı doğa, teknoloji veya insan kaynaklı olay” olarak da tanımlanmaktadır. ${ }^{2}$ Afetler doğal afetler ve teknolojik afetler olarak iki ana gruba ayrılır. Doğal afetler; jeofizik, meteorolojik, hidrolojik, klimatolojik, biyolojik ve dünya dışı olmak üzere alt gruplara ayrılırken teknolojik afetler; endüstriyel kazalar, taşıma kazaları ve çeşitli kazalar olarak gruplandırılır. ${ }^{3}$ Uluslararası Afet Veritabanı (The International Disaster Database / EM-DAT) verilerine göre, 2018 yılında dünya genelinde 68 milyondan fazla insanı etkileyen, 11804 ölüme neden olan ve 131.7 milyar dolar ekonomik kayıp nedeni olan 315 doğal afet olayı yaşanmıştır. ${ }^{4}$

Türkiye bulunduğu konum itibari ile her zaman çeşitli doğal afetleri yaşama riskine sahip olan bir ülkedir. Bu nedenle meydana gelen doğal olaylar; büyük ölçüde can kayıpları, yaralanmalar ve mal kayıplarına yol açarak afet sonucunu doğurmaktadır. Türkiye'de görülen doğal afetler; başta deprem olmak üzere, heyelan, su baskınları, erozyon, çı̆̆, kaya düşmeleri ve kuraklıktır. ${ }^{5}$ Risk Yönetim Endeksi (INFORM) endeks puanına göre afet oluşma riskine göre ülkeler 0-2 puan çok düşük risk, 2-3,5 puan düşük risk, 3,5-5 puan orta risk, 5-6,5 puan yüksek risk, 6,5-10 puan ise çok yüksek risk grubu olarak sınıflandırılmaktadır. Türkiye; 2018 raporuna göre INFORM endeks puanı 5,0 olarak hesaplanarak yüksek risk grubunda yer almıştır. ${ }^{6}$ EM-DAT verilerine göre ise Türkiye'de 19232016 yılları arasında toplam 313 afet yaşanmış olup bunların \%51,1'i (n=160) doğal, \%48,9'u (n=153) teknolojik afet olarak raporlanmıştır. Bunların sonucunda yaşanan toplam can kaybı ise 91.797 olarak gösterilmiştir. ${ }^{7}$ Başta deprem olmak üzere oluşabilecek doğal, teknolojik ya da insan kaynaklı afetler karşısında meydana gelecek zararların ve kayıpların büyük olacağı öngörülmektedir. ${ }^{8}$

Her ne kadar afetleri önlemek mümkün olmasa da herhangi bir zamanda meydana gelebilecek bir afete karşı hazırlıklı olunarak, afetin doğurabileceği olumsuz sonuçları en aza indirmek mümkündür. Afetlerden doğan tehlikeleri ve riskleri alınabilecek koruyucu önlemlerle azaltmak ve afet ortamına kısa sürede uyum sağlamak için eğitimli bir toplum gerekmektedir. Afet sonrasında yapılacak bilinçli müdahaleler kadar, afetler oluşmadan önce toplumun bilgilendirilmesi ve eğitimi de büyük önem taşımaktadır. Mühendislik fakültesi öğrencileri, aldıkları mesleki eğitim gereğince oluşabilecek afetlere dayanıklı yapıların üretilmesi noktasında kilit rol oynayabilir. Eğitimleri süresince bu konudaki farkındalıklarının sağlanması için öğrencilerin öncelikle afetler konusundaki bilgi, tutum ve davranışlarının belirlenmesi gerekir. Geleceğin hekimleri olan tıp fakültesi öğrencileri ise afet dönemlerinde sağlık personeli olarak görev alması sebebiyle afet konusundaki bilgi düzeylerinin ortaya konulması gerekir. Bütün bunlar değerlendirildiğinde; eğitim düzeyi yüksek olan üniversite öğrencilerinin afet konusundaki bilgi düzeylerini ölçmek, tutum ve davranışlarını belirlemek, sonrasında yapılacak eğitim planları için yol gösterici olacaktır.

Bu nedenle çalışmamızda İnönü Üniversitesi Tip ve Mühendislik fakültelerinde öğrenim gören öğrencilerin afet konusundaki bilgi, tutum ve davranışlarını saptamak amaçlanmıştır.

\section{GEREÇ ve YÖNTEMLER}

Mayıs 2019-Ağustos 2019 tarihleri arasında yapılmış olan bu çalışma; tanımlayıcı tipte kesitsel bir çalışmadır. Çalışmanın yapılabilmesi için Tıp Fakültesi ve Mühendislik Fakültesi Dekanlığından yazılı izin ve İnönü Üniversitesi Bilimsel Araştırma ve Yayın Etiği Kurulu’ndan 11.04.2019 tarihli 2019/8-28 sayı nolu etik kurul onayı alınmıştır. Bu çalışmanın evrenini İnönü Üniversitesi Tip Fakültesinde okuyan 1650 ve Mühendislik Fakültesinde okuyan 3320 
öğrenci oluşturmaktadır. Örneklem büyüklüğü hesaplarken; \%95 güven aralığında \%80 güçle referans çalışmanın tıp fakültesi öğrencilerinde afet çantası olanların oranı \%28.6 alındığında 297 olarak hesaplanmış olup, 316 öğrenciye ulaşılmıştır. ${ }^{9}$ Öğrenciler önce eğitim görülen fakülteye göre tabakalara ayrılmış daha sonra basit rastgele örnekleme metodu ile fakültelerden öğrenciler seçilmiştir. Verilerin toplanmasında kullanılan anket formu üç bölümden oluşmaktadır. Anketin birinci bölümünde sosyodemografik sorular, ikinci bölümünde bireyin afet konusundaki bilgi, tutum ve davranışlarını ölçen sorular, üçüncü bölümünde ise Genel Afet Hazırlık İnanç Ölçeği (GAHİÖ) yer almaktadır.

Genel Afet Hazırlık İnanç Ölçeği, İnal tarafından 2018 yılında geliştirilmiştir. 31 maddeden oluşan bu ölçek 5’li Likert tipindedir. Ölçeğin alt grupları; algılanan duyarlılık, algılanan ciddiyet, algılanan yarar, algılanan engeller, eyleme geçiriciler, öz yeterlilik olmak üzere 6 alt gruptan oluşur. Ölçeğin, 4-6-8-13-14-15-16-17-18-19-23-25-26-30 maddeleri olumsuz ifadeler olup tersine puanlanmaktadir. Ölçek; 1=Kesinlikle Katılmıyorum, 5=Kesinlikle Katılıyorum şeklinde 5'li Likert ölçeğidir. Ölçekteki her bir soru 1-5 puan üzerinden değerlendirilir. Ölçek puanının hesaplanması her bir maddenin aldığı puanların toplamından elde edilir. Ölçeğin değerlendirilmesinde; toplam puanın yükselmesi olumlu bilgi, tutum ve davranış eğilimini gösterirken, azalması olumsuz bilgi, tutum ve davranış eğilimi olduğunu göstermektedir. Ölçeğin Cronbach Alfa değeri $0,86^{\prime}$ dir. $^{10}$

Çalışmanın bağımlı değişkeni GAHIÖ toplam puanı olup bağımsız değişkenleri; yaş, cinsiyet, fakülte, afet yaşama durumu, afet çantasının olma durumu gibi değişkenlerdir.

Verilerin analizinde SPSS 22.0 paket programı kullanılmıştır. Yapılan Kolmogorov-Smirnov normal dağılıma uygunluk testine göre Genel Afet Hazırlık İnanç Ölçeği toplam puanın normal dağılıma uygun olduğu görülmüştür ( $p>0,05)$. İstatistiksel analizlerde; Student T Testi, One

Way Anova testleri kullanılmış olup, tüm değerlendirilmelerde $\mathrm{p}<0.05$ değeri anlamlı olarak kabul edilmiştir.

\section{BULGULAR}

Araştırmaya katılan öğrencilerin sosyodemografik özelliklerinin dağılımı Tablo 1'de verilmiştir. Öğrencilerin yaş ortancası 22(18-38)dir. Öğrencilerin \%41,90’ı kadın, \%58,10'u erkektir. Çalışmadaki Tip Fakültesinde okuyan öğrencilerin oranı \%35,69 iken Mühendislik Fakültesi öğrencilerinin oranı \%64,31'dir. Öğrencilerin \%44,62'si ailesiyle birlikte kalırken, \%31,65'i yurtta, \%17,72’i arkadaşları ile evde, \%6,01'i ise tek başına evde kalmaktadır.

Tablo 1. Çalışmaya Katılan Öğrencilerin Sosyodemografik Özelliklerinin Dağılımı

\begin{tabular}{|c|c|c|}
\hline Sosyodemografik Özellikler & $\mathbf{n}$ & $\%$ \\
\hline \multicolumn{3}{|l|}{ Cinsiyet (n:315) } \\
\hline Kadın & 132 & 41,90 \\
\hline Erkek & 183 & 58,10 \\
\hline \multicolumn{3}{|l|}{ Fakülte (n:311) } \\
\hline Tip Fakültesi & 111 & 35,69 \\
\hline Mühendislik Fak. & 200 & 64,31 \\
\hline Yaş(ortanca min-max) (n:312) & \multicolumn{2}{|c|}{$22(18-38)$} \\
\hline \multicolumn{3}{|l|}{ Anne Eğitim Durumu (n:315) } \\
\hline İlkokul ve altı & 148 & 46,98 \\
\hline Ortaokul & 50 & 15,87 \\
\hline Lise & 68 & 21,59 \\
\hline Üniversite ve üzeri & 49 & 15,56 \\
\hline \multicolumn{3}{|l|}{ Baba Eğitim Durumu (n: 316) } \\
\hline İlkokul ve altı & 74 & 23,42 \\
\hline Ortaokul & 53 & 16,77 \\
\hline Lise & 90 & 28,48 \\
\hline Üniversite ve üzeri & 99 & 31,33 \\
\hline \multicolumn{3}{|l|}{ Şu anda Yaşadığı Yer (n:316) } \\
\hline Evde tek & 19 & 6,01 \\
\hline Arkadaşlarla ev & 56 & 17,72 \\
\hline Aileyle ev & 141 & 44,62 \\
\hline Yurt & 100 & 31,65 \\
\hline
\end{tabular}


Tablo 2'de araştırmaya katılan öğrencilerin afet yaşama durumu ve afet ile ilgili bazı sorulara verilen cevapların dağılımı verilmiştir. Araştırmaya katılan öğrencilerin \%52,85’i daha önce herhangi bir afet durumu ile karşılaştığını ifade ederken, öğrencilerin en fazla yaşadığı afet deprem olarak ifade edilmiştir. Öğrencilerin \%23,17'si yaşadıkları yerde dolap, ayna, mobilya gibi eşyaları sabitlediğini i \%79,04’ü ise kendilerini olası afetlere karşı hazırlıklı görmediğini belirtmiştir. Öğrencilerin \%81,64’ü ise afet ile ilgili eğitim almak istediğini, \%65,82'si yaşadığı bölgede oluşabilecek afetlere karşı kendini endişeli hissettiğini belirtmiştir.

\begin{tabular}{|c|c|c|}
\hline \multicolumn{3}{|c|}{$\begin{array}{l}\text { Tablo 2. Çalışmaya Katılan Öğrencilerin Afet İle İlgili Bazı } \\
\text { Sorulara Verilen Cevapların Dağılımı }\end{array}$} \\
\hline Sosyodemografik Özellikler & $\mathrm{n}$ & $\%$ \\
\hline \multicolumn{3}{|c|}{ Herhangi bir afetle karşılaşma durumu(n:316) } \\
\hline Evet & 167 & 52,85 \\
\hline Hayır & 149 & 47,15 \\
\hline \multicolumn{3}{|l|}{ Karşılaşılan afetin tipi(n:198) } \\
\hline Deprem & 146 & 46,20 \\
\hline Sel & 17 & 5,38 \\
\hline Heyelan & 4 & 1,27 \\
\hline Yangin & 19 & 6,01 \\
\hline Ylldırım & 7 & 2,21 \\
\hline Çı̆̆ & 2 & 0,63 \\
\hline Diğer & 3 & 0,95 \\
\hline \multicolumn{3}{|c|}{ Yaşanılan yerde afet acil durum planı varlığı (n:315) } \\
\hline Evet & 54 & 17,14 \\
\hline Hayır & 133 & 42,22 \\
\hline Bilmiyorum & 128 & 40,64 \\
\hline \multicolumn{3}{|c|}{ Yaşanılan yerde dolap, ayna, mobilya sabitlenmesi(n:315) } \\
\hline Evet & 73 & 23,17 \\
\hline Hayır & 242 & 76,83 \\
\hline \multicolumn{3}{|c|}{ Hazırda bulundurulan afet çantası varlığı(n:316) } \\
\hline Evet & 18 & 5,70 \\
\hline Hayır & 298 & 94,30 \\
\hline \multicolumn{3}{|c|}{ Afetle ilgili eğitim alma durumu(n:316) } \\
\hline Evet & 133 & 42,09 \\
\hline Hayır & 183 & 57,91 \\
\hline \multicolumn{3}{|c|}{ Afet ile ilgili eğitim alınan kaynak(n:176) } \\
\hline Televizyon & 12 & 3,79 \\
\hline İnternet ortamı & 19 & 6,01 \\
\hline
\end{tabular}

\begin{tabular}{|l|c|c|}
\hline Okul & 125 & 39,55 \\
\hline Diğer & 20 & 6,32 \\
\hline $\begin{array}{l}\text { Yaşanılan bölgede oluşabilecek afetlere karşı endişe durumu } \\
\text { (n:316) }\end{array}$ \\
\hline Endişeli & 208 & 65,82 \\
\hline Endişeli değil & 58 & 18,36 \\
\hline Kararsız & 50 & 15,82 \\
\hline $\begin{array}{l}\text { Anketlerde eksik cevaplar olduğundan soruların her bir özellik } \\
\text { için verilen toplam cevap sayısı farklıdır. }\end{array}$ \\
\hline
\end{tabular}

Çalışmaya katılan öğrencilerin çeşitli değişkenlere göre GAHİÖ puan ortalamaları Tablo 3'te gösterilmiştir. Kadınların GAHİÖ puan ortalaması $(111,18 \pm 12,37)$ erkeklerin GAHİÖ puan ortalamasından $(106,90 \pm 12,80)$ anlamlı olarak yüksektir $(\mathrm{p}=0,003)$. Öğrencilerin okuduğu fakülteye göre GAHİÖ puan ortalamalarına bakıldığında; tıp fakültesinde okuyan öğrencilerin puan ortalaması $107,43 \pm 11,75$, mühendislik fakültesinde okuyan öğrencilerin puan ortalaması 109,37 $\pm 13,31$ olup fakülteye göre puan ortalamaları arasında anlamlı farklılık yoktur $(\mathrm{p}=0,194)$. Afet çantası olan öğrencilerin GAHIÖ puan ortalaması $118,72 \pm 15,67$, olmayan öğrencilerin GAHİÖ puan ortalaması 108,05 $\pm 12,35$ olup; afet çantası olan öğrencilerin GAHİÖ puan ortalamaları anlamlı olarak yüksektir $(\mathrm{p}=0,001)$. Olası afetlere karşı kendini hazırlıklı gören öğrencilerin GAHİÖ puanları hazırlıklı görmeyenlerden, afet ile ilgili herhangi bir eğitim alan öğrencilerin puanları ise almayanlardan anlamlı olarak yüksektir $(\mathrm{p}<0,05)$. Yaşadı̆̆ gede oluşabilecek afetlere karşı endişeli olan öğrencilerin GAHİÖ puan ortalaması, endişeli olmayan ve kararsız olan öğrencilerin puan ortalamalarından; yaşadığı bölgenin afet riskini bilen öğrencilerin GAHİ̈ puan ortalaması bilmeyen öğrencilerden anlamlı olarak yüksektir $(p<0,05)$. 


\begin{tabular}{|c|c|c|}
\hline \multicolumn{3}{|c|}{$\begin{array}{l}\text { Tablo 3. Çalışmaya Katılan Öğrencilerin Çeşitli Değişken- } \\
\text { lere Göre Genel Afet Hazırlık İnanç Ölçeği Puanlarının } \\
\text { Karşılaştırılması }\end{array}$} \\
\hline & $\begin{array}{l}\text { Genel Afet Hazırlık } \\
\text { Ölçeği Toplam } \\
\text { Puanı }\end{array}$ & $\mathbf{P}$ \\
\hline \multicolumn{3}{|l|}{ Cinsiyet } \\
\hline Kadın & $111,18 \pm 12,37$ & $0,003^{*}$ \\
\hline Erkek & $106,90 \pm 12,80$ & \\
\hline \multicolumn{3}{|l|}{ Fakülte } \\
\hline Tip Fakültesi & $107,43 \pm 11,75$ & 0,194 \\
\hline Mühendislik Fakültesi & $109,37 \pm 13,31$ & \\
\hline \multicolumn{3}{|c|}{ Ailede afet yaşayan birinin varlığı } \\
\hline Evet & $110,14 \pm 13,51$ & $0,027^{\star}$ \\
\hline Hayır & $106,93 \pm 11,79$ & \\
\hline \multicolumn{3}{|c|}{ Yaşanılan yerde afet acil durum planı varlığı } \\
\hline Evet $^{\mathrm{a}}$ & $113,18 \pm 13,31$ & \\
\hline Hayır $^{\mathrm{b}}$ & $106,88 \pm 12,33$ & $0,009^{* *}$ \\
\hline Bilmiyorum $^{\mathrm{b}}$ & $108,50 \pm 12,64$ & \\
\hline \multicolumn{3}{|l|}{ Afet Çantasının Varlığı } \\
\hline Evet & $118,72 \pm 15,67$ & $0,001^{*}$ \\
\hline Hayır & $108,05 \pm 12,35$ & \\
\hline \multicolumn{3}{|c|}{ Kendini olası afetlere karşı hazırlıklı görme durumu } \\
\hline Evet & $112,83 \pm 14,26$ & $0,003^{*}$ \\
\hline Hayır & $107,59 \pm 12,16$ & \\
\hline \multicolumn{3}{|c|}{ Afet ile ilgili eğitim alma durumu } \\
\hline Evet & $110,97 \pm 12,86$ & $0,006^{*}$ \\
\hline Hayır & $106,97 \pm 12,43$ & \\
\hline \multicolumn{3}{|c|}{ Yaşanılan bölgede oluşabilecek afetlere karşı endişe durumu } \\
\hline Endişeli $^{\mathrm{c}}$ & $111,23 \pm 12,60$ & \\
\hline Endișeli değil ${ }^{\mathrm{d}}$ & $103,65 \pm 12,52$ & $0,0001^{\star *}$ \\
\hline Kararsiz $^{\mathrm{d}}$ & $103,76 \pm 10,66$ & \\
\hline \multicolumn{3}{|c|}{ Yaşanılan bölgenin afet riskini bilme durumu } \\
\hline Bilgisi var & $111,08 \pm 12,81$ & $0,001^{*}$ \\
\hline Bilgisi yok & $104,58 \pm 11,69$ & $0,001^{*}$ \\
\hline \multicolumn{3}{|l|}{$\begin{array}{l}\text { a, b den farklıdır. } \\
\text { c,d den farklıdır. } \\
{ }^{\star} \text { Student } t \text { testi } \\
{ }_{* \star} \text { One Way- ANOVA }\end{array}$} \\
\hline
\end{tabular}

\section{TARTIŞMA}

Çalışmamıza katılan öğrencilerin \%52,85’i daha önce herhangi bir afet yaşadığını ifade etmiştir. Ülkemizde yapılan diğer çalışmalara bakıldığında; katılımcıların afet yaşama durumu \%18,60 ile \%89,50 arasında iller arasında değişen oranlarda gözlenmektedir. ${ }^{11-15}$ Elde edilen verilerin farkl1lığı, katılımcıların yaşadıkları illerin farklı oranlarda afet riski taşımasından kaynaklanan bir sonuç olabilir. Çalışmamızda aile fertlerinde afet durumuyla karşılaşanların yüzdesi \%52,87 olup; Burdur ilinde yapılan çalışmada, aile fertlerinde afet yaşayanların yüzdesi $(\% 49,90)$ kendisi afet ile karşılaşanlardan daha fazla olarak değerlendirilmiştir. ${ }^{12}$ Bu farklılık da göz önünde bulundurulduğunda iller arasında afet yaşama durumundaki farklılığa coğrafi konumun yanında, çalışmaya katılanların yaşları ve bireylerin afet kavramını algılamalarındaki farklılıklar da sebep olmuş olabilir.

Çalışmamızda öğrencilere yaşadıkları afetlerin neler olduğu sorulduğunda; \%46,20 oranı ile deprem ilk sırada karş1mıza çıkmıştır. Bunu sırasıyla yangın $(\% 6,01)$, sel $(\% 5,38)$, yıldırım $(\% 2,21)$, heyelan $(\% 1,27)$ ve diğer afetler $(\% 0,95)$ izlemektedir. Ülkemizde yapılan diğer çalışmalarda da ilk sırayı deprem alırken bunu sel, yangın gibi afetlerin izlediği görülmüştür ${ }^{11,14,15}$. Türkiye nüfusunun $\% 71$ 'i 1 . ve 2 . derece deprem bölgesinde yaşamakta ve depremler yıkıcı etkilere büyük can ve mal kayıplarına sebep olarak, kişilerde travmatik sonuçlar doğurmaktadır. Bu da depremlerin daha fazla hatırlanmasına yol açabilmektedir. ${ }^{5}$

Çalışmamızda öğrencilere yaşanılan yerde afet acil durum planının varlığı sorulduğunda; öğrencilerin \%17,14'ü evet, \%42,22'si hayır, \%40,64'ü bilmiyorum cevabını vermiştir. Burdur'da yapılan çalışmada da öğrencilerin büyük çoğunluğunun $(\% 95,40)$ okul afet planı ile ilgili bilgiye sahip olmadığını belirtilmiştir. ${ }^{12} \mathrm{Bu}$ çalışmalardan anlaşıldığı üzere öğrencilerin büyük kısmı sıklıkla vakit geçirdikleri yerlerin dahi acil durum planlarını bilmemektedir. Bu durumun önlenmesi için acil durumlarda izlenmesi gereken yollar, bina tahliye planları gibi bilgiler öğrencilerin sık- 
lıkla kullandıkları alanlarda yer almalı, gerekirse fotoğraf, video ve tatbikatlarla sık sık hatırlatmalar yapılmalıdır.

Çalışmamızda tıp ve mühendislik fakültesi öğrencilerinin \%57,91'i afet konusunda herhangi bir eğitim almadıkları$\mathrm{n} ı$ ifade etmişlerdir. Afet ile ilgili eğitim alanların oranı az olup afet konusunda eğitim almak ister misiniz sorusuna \%81,64 evet cevabı verilmiştir. Ülkemizde yapılan bir araştırmada; öğrencilerin \%64,90’1 daha önce herhangi bir afet eğitimi almadığını belirtmiştir9. Çalışmamızla benzer olarak, çeşitli ülkelerde yapılan çalışmalarda da sağlık çalışanları, üniversite öğrencileri veya toplum bazında ortak bir sonuç olarak; çalışmaya katılanların büyük çoğunluğu afet konusunda eğitim almak istediklerini belirtmişlerdir ${ }^{14,16-18}$. $\mathrm{Bu}$ durum bireylerin afet konusundaki bilgi eksikliklerinin farkında olduğunu ve daha fazla bilgi sahibi olmaya istekli olduklarını göstermektedir.

Yapılan farklı çalışmalarda mühendislik ve tıp fakültesi öğrencilerinin afete hazırlık, bilgi ve farkındalık düzeylerinin diğer fakültelere göre daha yüksek olduğu görülmüştür., ${ }^{9,19}$ Çalışma grubunda fakülteye göre afet konusunda bilgi, tutum ve davranış puanlarının benzer olduğu görülmüştür. Mühendislik fakültesi öğrencilerinin; meslek yaşamları açısından afet konusunun ilgi alanlarında olması, tıp fakültesi öğrencilerinin ise afetlerde sağlık personeli olarak aktif yer almaları sebebiyle farkındalıklarının olması benzer puanlar almalarına sebep olmuş olabilir.

Araştırmaya katılan öğrencilerin büyük bir kısmının $(\% 94,30)$ hazırda bulundurdukları bir afet çantasının olmadığını belirtmiştir. Burdur'da yapılan bir çalışmada üniversite öğrencilerinin \%86,70’i afet çantası bulundurmadığını ifade etmiştir. ${ }^{12}$ Afet çantası bulundurma oranlarının az olması öneminin yeteri kadar kavranamadığını göstermektedir.

Çalışmamızda afet ile ilgili herhangi bir eğitim alan öğrencilerin almayanlara göre, herhangi bir tatbikata katılan öğrencilerin katılmayanlara göre ölçek puanları anlamlı derecede yüksek bulunmuştur. Benzer şekilde ülkemizde yapılan çalışmalar da göstermektedir ki afet eğitimi veya afet tatbikatlarına katılan bireylerin bilgi ve farkındalık düzeyi anlamlı derecede yüksektir. ${ }^{13,15,19,20} \mathrm{Bu}$ da eğitimlerin ve tatbikatların afetlere hazırlık konusunda ne kadar önemli ve etkili olduğunu göstermektedir.

"Kendinizi olası afetlere karşı hazırlıklı görüyor musunuz" sorusuna öğrenciler \%78,80 hayır cevabını vermiştir. Benzer şekilde Antakya ve Burdur'da yapılan çalışmalarda da katılımcılar çok büyük oranlarda $(\% 74,80, \% 78,30)$ kendilerini olası afetlere karşı hazır hissetmediklerini belirtmişlerdir. ${ }^{11,12}$ Öğrencilerde afetlere karşı hazırlıklı olma tutumunu oluşturmak için afet durumunda yapılması gerekenlerin belirli aralıklarla, düzenli bir şekilde çeşitli etkinliklerde eğitim ve tatbikatlar yapılmalıdır.

Afetler her an karşımıza çıkabilecek bir tehlike olması sebebiyle ve bu konuda özellikle üniversite öğrencilerinin farkındalıklarının arttırılması, eğitilmesi, bilgilendirilmesi ve afetlere hazır hale getirilmesi büyük önem taşımaktadır.

\section{Etik Kurulu Onayı}

İnönü Üniversitesi Bilimsel Araştırma ve Yayın Etiği Kurulu'ndan 11.04.2019 tarihli 2019/8-28 sayı nolu etik kurul onayı alınmıştır. 
Sakarya Tip Dergisi 2020;10(4):580-586

YíĞİT ve Ark., İki Fakülte Öğrencilerinin Afet Bilgi, Tutum ve Davranışları

\section{Kaynaklar}

1. 1World Health Organization. Available at: https://www.who.int/hac/techguidance/preparedness/en/. Erişim tarihi : 06.09.2019

2. Başbakanlık Afet ve Acil Durum Yönetimi Başkanlı̆̆l, Açıklamalı Afet Terimleri Sözlüğü. Ankara, 2014

3. EM-DAT. Available at: https://www.emdat.be/explanatory-notes Erișim tarihi:06.09.2019

4. EM-DAT Natural Disasters 2018. Available at: https://www.emdat.be Erișim tarihi :06.09.2019

5. Ergünay O. Türkiye'nin Afet Profili. TMМOB Afet Sempozyumu Bildiriler Kitabl. 2007; 5-7.

6. https://www.afad.gov.tr/kurumlar/afad.gov.tr/35429/xfiles/Turkiye_de_Afetler.pdf Erişim tarihi: 17.02.2020

7. Bahadır H, Uçku R. Uluslararası Acil Durum Veri Tabanına Göre Türkiye Cumhuriyeti Tarihindeki Afetler. Doğal Afetler ve Cevre Dergisi 2018; 4(1): 28-33.

8. Kadıoğlu M, Özdamar E. Modern, Bütünleșik Afet Yönetimin Temel İlkeleri. Afet Zararlartnı Azaltmanin Temel İlkeleri. 1. Baskı. Ankara: İsmat Matbaacilı; 2008.

9. Dökmeci AH, Merinç F. Namık Kemal Üniversitesi Öğrencilerinin Temel Afet Farkındalğ̆lnın Değerlendirilmesi. Afet ve Risk Dergisi 2018; 1(2): 106-113.

10. Inal E, Altintas KH, Dogan N. The Development of a General Disaster Preparedness Belief Scale Using The Health Belief Model as a Theoretical Framework. International Journal of Assessment Tools in Education 2018; 5(1): 146-158.

11. Özşahin E, Kaymaz ÇK. Afet Kültürünün Değerlendirilmesine Bir Örnek: Antakya Şehri. 2. Türkiye Deprem Mühendisliği ve Sismoloji Konferansl. 25-27 Eylül 2013 Hatay, Türkiye.

12. Șahin Y, Lamba M, Öztop S. Universite Öğrencilerinin Afet Bilinci ve Afete Hazırlı Düzeylerinin Belirlenmesi. Medeniyet Araștırmaları Dergisi 2018; 3(6): 149-159.
13. Şen G, Ersoy G. Hastane Afet Ekibinin Afete Hazırlık Konusundaki Bilgi Düzeylerinin Değerlendirilmesi. Gümüşhane Üniversitesi Sağllk Bilimleri Dergisi 2017; 6(4): 122-130.

14. Tașkıran G, Baykal Ü. Hemșirelerin Afetlere İliş̧kin Görüş̧leri Deneyimleri ve Hazırlık Algısı Nursesopinions Experiences and Preparedness Perceptions Related to Disasters. Uluslararası Hakemli Hemşirelik Araștırmaları Dergisi 2017; 10: 36-58.

15. İnal E, Kocagöz S, Turan M. Temel Afet Bilinç ve Hazırlk Düzeyinin Saptanmasına Yönelik Bir Araștırma. Türkiye Acil Tip Dergisi 2012; 12(1): 15-19.

16. Su T, Han X, Chen F, Du Y, Zhang H, Yin J, ... Cao G. Knowledge Levels And Training Needs Of Disaster Medicine Among Health Professionals, Medical Students, And Local Residents In Shanghai, China. PLOS One 2013; 8(6): 1-12.

17. Ragazzoni L, Ingrassia PL, Gugliotta G, Tengattini M, Franc JM, Corte FD. Italian Medical Students And Disaster Medicine: Awareness and Formative Needs. American Journal of Disaster Medicine 2013; 8(2): 127-136.

18. Markenson D, Woolf S, Redlener I, Reilly M. Disaster Medicine and Public Health Preparedness of Health Professions Students: A Multidisciplinary Assessment of Knowledge, Confidence, and Attitudes. Disaster Medicine and Public Health Preparedness 2013; 7(5): 499-506.

19. Gerdan S. Determination of Disaster Awareness, Attitude Levels and Individual Priorities at Kocaeli University. Eurasian Journal of Educational Research 2014; 55: 159-176.

20. Sevinç Ö, Güner Y, Til A. Çanakkale İli 112 Acil Sağlık Hizmetleri İstasyonlarnnda Çalışan Personelin Afet Tibbı Konusundaki Bilgi Düzeyleri. Pamukkale Tip Dergisi 2017; 11(2): 119-125. 